\title{
Outcomes Are Not Different between Patients with Intermediate and High DWI-ASPECTS after Stent-Retriever Embolectomy for Acute Anterior Circulation Stroke
}

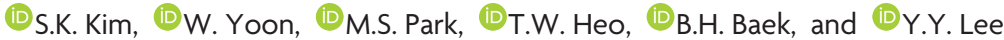

\begin{abstract}
BACKGROUND AND PURPOSE: Questions remain as to what benefits embolectomy provides to patients presented with considerable early ischemic changes on baseline imaging studies. This study aimed to investigate the impact of the Alberta Stroke Program Early CT Score applied to DWI on treatment outcomes in patients with acute stroke undergoing stent-retriever embolectomy.
\end{abstract}

MATERIALS AND METHODS: We retrospectively analyzed the clinical and DWI data from 171 patients with acute anterior circulation stroke who were treated with stent-retriever embolectomy within 6 hours of symptom onset. DWI-ASPECTS scores were analyzed with the full scale or were dichotomized (4-6 versus 7-10). Patients with DWI-ASPECTS $\leq 3$ were excluded from the study. Associations between outcome and clinical and radiologic factors were determined with a multivariate logistic regression analysis. A good outcome was defined as a modified Rankin Scale score of $0-2$ at 3 months.

RESULTS: The median DWI-ASPECTS was 7 (interquartile range, 6-8). The rates of good outcome, symptomatic hemorrhage, and mortality were not different between high DWI-ASPECTS (scores of 7-10) and intermediate DWI-ASPECTS (scores of 4-6) groups. In patients with an intermediate DWI-ASPECTS, good outcome was achieved in 46.5\% (20/43) of patients with successful revascularization, whereas no patients without successful revascularization had a good outcome $(P=.016)$. In multivariate logistic regression analysis, independent predictors of good outcome were age and successful revascularization.

CONCLUSIONS: Our study suggested that there were no differences in outcomes between patients with a high DWI-ASPECTS and those with an intermediate DWI-ASPECTS who underwent stent-retriever embolectomy for acute anterior circulation stroke. Thus, patients with an intermediate DWI-ASPECTS otherwise eligible for endovascular therapy may not be excluded from stent-retriever embolectomy or stroke trials.

ABBREVIATION: IQR = interquartile range

$\mathbf{R}$ ecent randomized controlled trials have shown that stentretriever embolectomy in addition to standard care was associated with improved functional outcome in patients with acute anterior circulation stroke due to large-vessel occlusion within $6-8$ hours of symptom onset. ${ }^{1-5}$ For further advancement in treating acute anterior circulation stroke, it is becoming important to more clearly refine the selection criteria for stent-retriever embolectomy. Several clinical and imaging factors are known to be associated with functional outcomes after endovascular treat-

Received September 15, 2015; accepted after revision November 23.

From the Departments of Radiology (S.K.K., W.Y., T.W.H., B.H.B., Y.Y.L.) and Neurology (M.S.P.), Chonnam National University Medical School, Chonnam National University Hospital, Gwangju, Republic of Korea.

Please address correspondence to Woong Yoon, MD, Department of Radiology, Chonnam National University Hospital, 42 Jebong-ro, Dong-gu, Gwangju, 501-757, Republic of Korea; e-mail: radyoon@jnu.ac.kr

http://dx.doi.org/10.3174/ajnr.A4663 ment for acute anterior circulation stroke. ${ }^{6-9}$ However, questions remain as to what benefits embolectomy provides to patients who present at extended time periods or those with considerable early ischemic changes on baseline imaging studies. Furthermore, the imaging technique that best determines candidacy for embolectomy in these patients remains unknown.

ASPECTS is a 10-point semiquantitative scoring system, which was developed to offer the simplicity and reliability of CT to assess early ischemic changes in patients with acute ischemic stroke in the anterior circulation. ${ }^{10}$ ASPECTS has recently been applied to DWI, which is much more sensitive and accurate in the detection of acute infarction than noncontrast CT. ${ }^{11-14}$ A recent study showed that interrater agreement for DWI-ASPECTS was superior to that for CT-ASPECTS and that DWI-ASPECTS outperformed CT-ASPECTS in predicting functional outcome at 90 days. ${ }^{9}$ The DWI-ASPECTS can also provide similar risk assessment far more rapidly than measurement of the infarct volume 
on DWI, an independent predictable marker of the clinical outcome, in patients with anterior circulation stroke. ${ }^{9,15-17}$ However, few studies have investigated the association between pretreatment DWI-ASPECTS and functional outcome after stent-retriever embolectomy in patients with acute anterior circulation stroke. ${ }^{9,14,18}$

Although several studies showed that a DWI-ASPECTS of 7 was the optimal cutoff value for predicting clinical outcomes in patients undergoing intra-arterial or IV pharmacologic thrombolysis, ${ }^{19-21}$ results of recent studies have suggested that some patients with a DWI-ASPECTS of $<7$ may still benefit from complete recanalization. ${ }^{14}$ Successful revascularization can be achieved more frequently by using stent-based embolectomy than by using pharmacologic thrombolysis or other mechanical devices. ${ }^{1-5}$ In this context, patients with acute stroke and a DWIASPECTS of $<7$ might have a similar chance of a good outcome compared with those with a higher DWI-ASPECTS if they are treated with stent-retriever embolectomy in a short time window. However, this hypothesis has not been tested. Thus, this study aimed to investigate the impact of DWI-ASPECTS on functional outcome in patients with acute anterior circulation stroke who underwent stent-retriever embolectomy.

\section{MATERIALS AND METHODS \\ Patients}

From December 2010 to December 2013, 190 consecutive patients presenting with acute ischemic stroke due to internal carotid artery or middle cerebral artery occlusions were treated with stent-retriever embolectomy at a comprehensive regional stroke center. Patients underwent a nonenhanced CT scan and multimodal MR imaging before endovascular embolectomy procedures. Of these patients, those who had DWI of insufficient quality for reliable evaluation $(n=3)$ or a DWI-ASPECTS of $\leq 3$ $(n=6)$ or a previous modified Rankin Scale score of $\geq 2(n=4)$ or concomitant anterior and posterior circulation infarction $(n=$ 6) were excluded; thus, 171 patients were left in this study. We prospectively collected the following clinical and radiologic data of these 171 patients: demographic features, cerebrovascular risk factors, NIHSS scores on admission, use of IV thrombolysis, time to endovascular treatment, procedure time, time to reperfusion, revascularization status, and clinical outcome. The institutional ethics committee approved this study. For each patient, written informed consent for endovascular therapy was obtained from a family member.

\section{MR Imaging Analysis}

MR imaging examinations were performed by using a $1.5 \mathrm{~T}$ unit (Signa HDxt; GE Healthcare, Milwaukee, Wisconsin). Before the endovascular procedure, patients underwent MR imaging, including DWI, gradient-echo imaging, a FLAIR sequence, 3D TOF-MRA, and perfusion imaging. DWI sequences were obtained in the axial plane by using a single-shot, spin-echo echoplanar technique with the following parameters: TR of 9000 $\mathrm{ms}$, TE of $80 \mathrm{~ms}$, section thickness of $4 \mathrm{~mm}$, intersection gap of $0 \mathrm{~mm}$, FOV of $260 \times 260 \mathrm{~mm}$, and b-values of 0 and 1000 $\mathrm{s} / \mathrm{mm}^{2}$. DWI-ASPECTS was assessed by 2 neuroradiologists (with 2 and 4 years of experience, respectively) who were blinded to any clinical information. Conclusions were reached by consensus.

\section{Endovascular Treatment}

On admission, a stroke neurologist performed a neurologic assessment based on the NIHSS. The inclusion criteria for stentretriever embolectomy were as follows: presentation within 6 hours of stroke onset, baseline NIHSS score of $\geq 4$, no intracranial hemorrhage detected on cranial CT or MR imaging, a target mismatch pattern on multimodal MR imaging based on visual estimation (time-to-peak map of perfusion imaging showing a lesion volume $\geq 30 \%$ larger than that detected with diffusion imaging), and infarct volume on diffusion imaging or nonenhanced CT of less than one-third of the MCA territory.

Cerebral angiography and endovascular therapy were performed with the patient under conscious sedation. In cases of agitation, an intravenous bolus of midazolam was given and repeated if necessary. Stent-based embolectomy with a Solitaire stent (Covidien, Irvine, California) was performed as the first-line endovascular treatment. When stent-based embolectomy was unsuccessful, additional mechanical approaches were performed, including manual aspiration embolectomy with a Penumbra System reperfusion catheter (Penumbra, Alameda, California). The details of the techniques used for mechanical embolectomy were previously described. ${ }^{22,23}$ Revascularization status was assessed on the final angiogram and was classified according to the modified TICI scale, ${ }^{24}$ and successful revascularization was defined as a modified TICI grade of $2 \mathrm{~b}$ or 3 . Clinical outcome was assessed by a stroke neurologist by using the mRS during an outpatient visit 3 months after treatment. If patients were unable to attend the outpatient clinic, outcomes were obtained via telephone interview. A good clinical outcome was defined as an mRS score of $\leq 2$.

\section{Statistical Analysis}

Continuous variables are presented as medians and interquartile ranges (IQRs). Discrete variables are presented as counts and percentages. First, the area under the receiver operating characteristic curve was applied to evaluate the prognostic performance of DWI-ASPECTS and the optimal cutoff value for discriminating a good outcome (defined as mRS $0-2$ at 3 months). Second, the differences in baseline characteristics and treatment outcomes between DWI-ASPECTS subgroups were determined. Patients were divided into 2 groups according to baseline DWI-ASPECTS for analysis of the prognostic impact on functional outcome; namely, a high DWI-ASPECTS group (scores of 7-10) and an intermediate DWI-ASPECTS group (scores of 4-6). The $\chi^{2}$ or Fisher exact test was used for comparing categoric variables, and the MannWhitney $U$ test was used for comparing continuous variables. Third, independent associations between functional outcome and clinical and radiologic factors were determined with a multivariate logistic regression analysis. The variables tested in the multivariate logistic regression models were those with $P<.2$ in the univariate analysis and time to treatment. Fourth, we further compared functional outcome between patients with or without successful revascularization (modified TICI, $\geq 2 \mathrm{~b}$ ) according to the DWI-ASPECTS subgroups to evaluate the impact of DWIASPECTS on the success of endovascular therapy. The $\chi^{2}$ or 


\begin{tabular}{|c|c|c|c|c|}
\hline & \multirow[b]{2}{*}{ Total $(N=171)$} & \multicolumn{2}{|c|}{ DWI-ASPECTS } & \multirow[b]{2}{*}{$P$ Value } \\
\hline & & $7-10(n=120)$ & 4-6 (n = 51) & \\
\hline Age (yr) (median) (IQR) & $72(63.5-78)$ & $73(65-78)$ & $68(60-74)$ & .014 \\
\hline Male sex & $88(51.5 \%)$ & $58(48.3 \%)$ & 30 (58.8\%) & .209 \\
\hline \multicolumn{5}{|l|}{ Risk factors } \\
\hline Hypertension & $95(55.6 \%)$ & $69(57.5 \%)$ & $26(51 \%)$ & .432 \\
\hline Diabetes mellitus & $32(18.7 \%)$ & $22(18.3 \%)$ & $10(19.6 \%)$ & .845 \\
\hline Coronary artery disease & 20 (11.7\%) & 14 (11.7\%) & $6(11.8 \%)$ & .985 \\
\hline Dyslipidemia & $42(24.6 \%)$ & $35(29.2 \%)$ & $7(13.7 \%)$ & $.034^{\mathrm{a}}$ \\
\hline Smoking & $46(26.9 \%)$ & $27(22.5 \%)$ & $19(37.3 \%)$ & $.059^{\mathrm{a}}$ \\
\hline Atrial fibrillation & $87(50.9 \%)$ & $64(53.3 \%)$ & $23(45.1 \%)$ & .324 \\
\hline Congestive heart failure & $6(3.5 \%)$ & $5(4.2 \%)$ & $1(1.9 \%)$ & $.670^{\mathrm{a}}$ \\
\hline History of stroke or TIA & $22(12.9 \%)$ & $18(15 \%)$ & $4(7.8 \%)$ & $.317^{\mathrm{a}}$ \\
\hline Intravenous thrombolysis & $104(60.8 \%)$ & $71(59.2 \%)$ & $33(64.7 \%)$ & .497 \\
\hline Time to treatment (min) (median) (IQR) & $245(190-310)$ & $257.5(190-315)$ & $220(190-281)$ & .155 \\
\hline Procedure time (min) (median) (IQR) & $33(20-50)$ & $34(20.5-50)$ & $30(20-43.5)$ & .444 \\
\hline Time to revascularization (min) (median) (IQR) & $280(223.5-352)$ & $297.5(228.5-355)$ & $252(221.5-326)$ & .136 \\
\hline Baseline NIHSS score (median) (IQR) & $13(10-16)$ & $12(9-15)$ & $15(12-18)$ & $<.001$ \\
\hline \multicolumn{5}{|l|}{ Stroke etiology } \\
\hline Large-artery atherosclerosis & $43(25.1 \%)$ & $32(26.7 \%)$ & $11(21.6 \%)$ & .482 \\
\hline Cardioembolism & $99(57.9 \%)$ & $70(58.3 \%)$ & $29(56.9 \%)$ & .859 \\
\hline Undetermined & $28(16.4 \%)$ & $17(14.2 \%)$ & $11(21.6 \%)$ & .231 \\
\hline
\end{tabular}

${ }^{a}$ Comparisons were performed using the Fisher exact test. Comparisons of categoric variables were performed using $\chi^{2}$ tests unless otherwise indicated.

Table 2: Outcomes after stent-retriever embolectomy in 171 patients

\begin{tabular}{lcccc}
\hline & & \multicolumn{2}{c}{ DWI-ASPECTS } & \\
\cline { 2 - 3 } & Total $(\boldsymbol{N}=171)$ & $\mathbf{7 - 1 0 ( n = 1 2 0 )}$ & $\mathbf{4 - 6}(\boldsymbol{n}=\mathbf{5 1})$ & $\boldsymbol{P}$ Value \\
\hline Modified TICI 2b or 3 & $144(84.2 \%)$ & $101(84.2 \%)$ & $43(84.3 \%)$ & .981 \\
Good outcome & $81(47.4 \%)$ & $61(50.8 \%)$ & $20(39.2 \%)$ & .164 \\
Symptomatic hemorrhage & $6(3.5 \%)$ & $4(3.3 \%)$ & $2(3.9 \%)$ & $1.000^{\text {a }}$ \\
Mortality & $16(9.4 \%)$ & $9(7.5 \%)$ & $7(13.7 \%)$ & .201 \\
\hline
\end{tabular}

${ }^{a}$ Comparisons were performed using the Fisher exact test. Comparisons of categoric variables were performed using $\chi^{2}$ tests unless otherwise indicated.

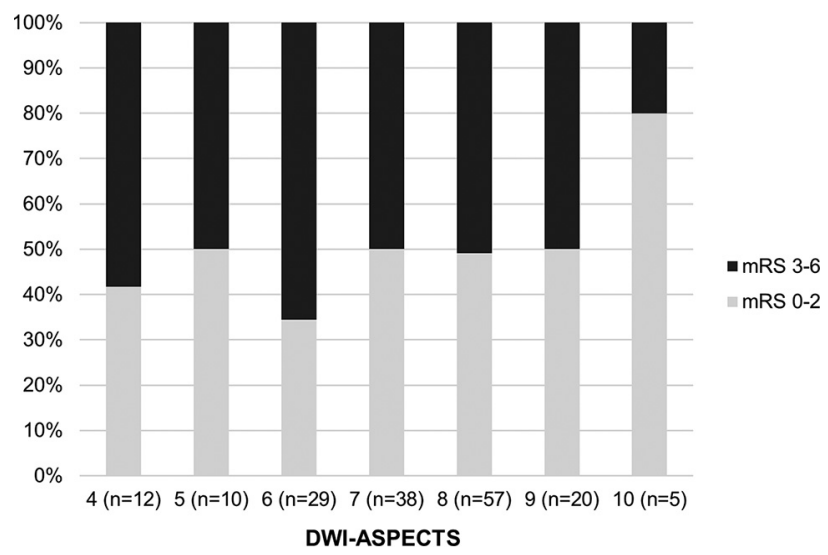

FIG 1. Functional outcome (mRS 0-6) of 171 patients with acute anterior circulation stroke according to pretreatment DWI-ASPECTS. The proportion of outcomes (mRS 0-2 versus mRS 3-6) within each DWI-ASPECTS is shown.

Fisher exact test was used for comparison. All statistical analyses were performed with SPSS software (Version 21.0; IBM, Armonk, New York). A $P$ value $<.05$ was significant.

\section{RESULTS}

One hundred seventy-one eligible patients ( 88 men and 83 women; mean age, 69.9 years; age range, 23-92 years) were identified. Clinical characteristics of the patients are shown in Table 1.

Of the 171 patients, 127 had occlusions in the middle cerebral artery and 44 had occlusions in the internal carotid artery. Overall, the median NIHSS score on admission was 13 (IQR, 10-16). The median time from symptom onset to endovascular therapy was 245 minutes (IQR, 190-310 minutes), and the median procedure time was 33 minutes (IQR, 20-50 minutes). The median time from symptom onset to revascularization was 280 minutes (IQR, 223.5-352 minutes).

In the entire cohort, the median DWI-ASPECTS was 7 (IQR, 6-8); 120 patients had a DWI-ASPECTS of $\geq 7$, and 51 patients had a DWI ASPECTS of 4-6. The median NIHSS score was significantly higher in patients with a DWI-ASPECTS of 4-6 than in those with a DWI-ASPECTS of $\geq 7$ ( 15 versus $12, P<.001$ ). There was a significant correlation between DWI-ASPECTS and admission NIHSS score $(P<.001)$. Age and dyslipidemia were also associated with DWI-ASPECTS (Table 1). Patients with an intermediate DWI-ASPECTS were significantly younger than those with a high DWI-ASPECTS $(P=.014)$.

Treatment outcomes of patients are summarized in Table 2. Overall, successful revascularization (modified TICI $2 \mathrm{~b}$ or 3 ) was achieved in $84.2 \%$ (144/171). In the entire cohort, $47.4 \%(81 / 171)$ had a good outcome and 3.5\% (6/171) had a symptomatic hemorrhage. Mortality was $9.4 \%(16 / 171)$ at 3 months.

\section{Impact of DWI-ASPECTS on Outcomes}

Three-month outcomes according to pretreatment DWIASPECTS are shown in the Fig 1. Receiver operating characteristic curve analysis showed that a DWI-ASPECTS of $\geq 7$ was the optimal cutoff to predict a good outcome at 3 months with an area under the curve of 0.57 (95\% CI, 0.483-0.656), a sensitivity of $75.3 \%$, and a specificity of $34.4 \%$ (Fig 2). Overall, $50.8 \%$ (61/120) of patients with a DWI-ASPECTS of $\geq 7$ and $39.2 \%$ (20/51) of patients with a DWI-ASPECTS of $4-6$ had a good outcome; this difference was not statistically significant $(P=.164)$ (Table 2). 
There were also no significant differences in the rates of successful revascularization, symptomatic hemorrhage, and mortality between patients with DWI-ASPECTS of 7-10 and those with scores of $4-6$.

When each year of age, each point of the NIHSS, time to treatment, symptomatic hemorrhage, DWI-ASPECTS (each score or dichotomized into 7-10 versus 4-6), and successful revascularization were selected into the multivariate logistic regression analysis, independent predictors of good outcome were age (OR, 0.941; 95\% CI, 0.909-0.974; $P=.001)$ and successful revascularization (OR, 8.511; 95\% CI, 2.298-31.525; $P=.001$ ) (Table 3).

\section{Impact of Revascularization on Outcomes among DWI-ASPECTS Subgroups}

There was no significant difference in the rate of successful revascularization between patients with a DWI-ASPECTS of 7-10 and those with a DWI-ASPECTS of $4-6$ (84.2\% versus $84.3 \%)$. In the high DWI-ASPECTS group, a good outcome was achieved more frequently in patients with successful revascularization than in those without $(58.4 \%$ versus $10.5 \%, P<.001)$. In this group, the OR for good outcome with successful revascularization was 11.94 (95\% CI, 2.62-54.47; $P<.001$ ). A similar relationship was found for the intermediate DWI-ASPECTS group. In this group, a good outcome was achieved in $46.5 \%$ (20/43) of patients with successful revascularization, whereas no patients without successful revascularization had a good outcome $(P=.016)$ (Fig 3$)$.

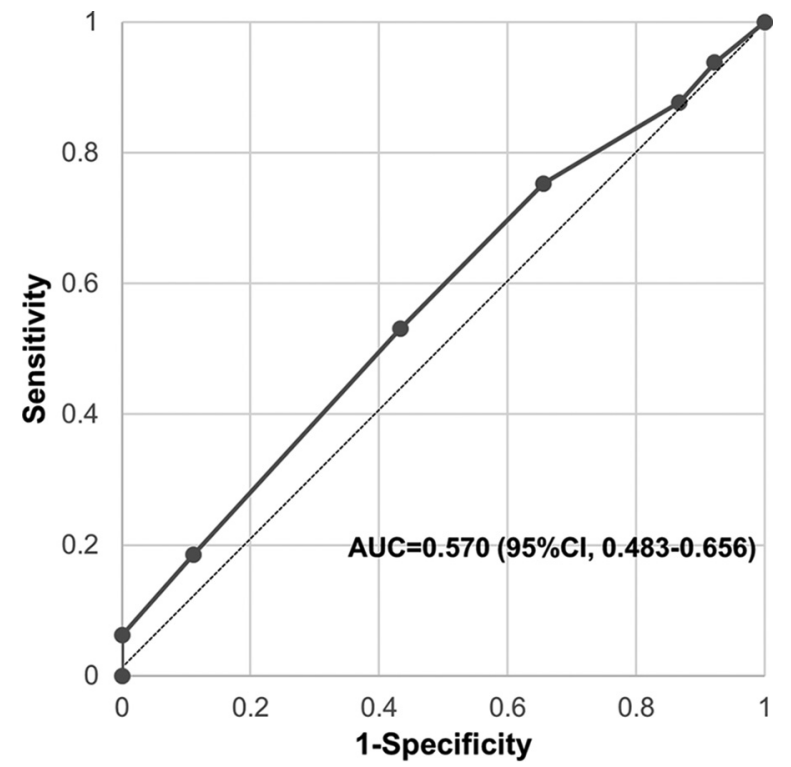

FIG 2. Receiver operating characteristic curve of DWI-ASPECTS for prediction of a good outcome (mRS $0-2$ at 3 months). AUC indicates area under the curve.

\section{DISCUSSION}

The present study showed that treatment outcomes are not significantly different between patients with a high DWI-ASPECTS of 7-10 and those with an intermediate DWI-ASPECTS of 4-6 who underwent stent-retriever embolectomy for acute anterior circulation stroke. There were no significant differences in the rates of successful revascularization, good outcome, symptomatic hemorrhage, and mortality between the 2 groups in our study.

Several factors might explain the finding that patients with an intermediate DWI-ASPECTS benefited from stent-retriever embolectomy in our study. First, stent-retriever embolectomy can achieve a dramatically increased rate of successful recanalization of up to $80 \%-90 \%$ without an increased risk of symptomatic hemorrhage, compared with intra-arterial pharmacologic thrombolysis or previous mechanical approaches. ${ }^{23}$ Recanalization is one of the most powerful independent predictors of good outcome in patients with acute stroke undergoing endovascular treatment. ${ }^{16,25-27}$ In our study, the overall rate of successful revascularization was $84 \%$, and it was identical among high and intermediate DWI-ASPECTS groups. The rate of symptomatic hemorrhage was quite low (3.5\%) in our study. Among the intermediate DWI-ASPECTS group, almost half of patients with recanalization had a good outcome in the present study. In addition, recanalization was one of the independent predictors of good outcome $(\mathrm{OR}=8.512)$, while DWI-ASPECTS was not. This finding is consistent with the results of a previous study by Inoue et al. ${ }^{14}$ In their study, patients with anterior circulation stroke were treated with various endovascular therapies, including IV/ intra-arterial thrombolysis and mechanical embolectomy with a snare or Solitaire stent, and $50 \%$ of patients with complete recanalization (Thrombolysis in Myocardial Infarction score of 3) in the subgroup with DWI-ASPECTS of $<5$ had a good outcome. ${ }^{14}$ Thus, the results of our study and the study of Inoue et al ${ }^{14}$ suggest that recanalization is far more important than pretreatment DWI-ASPECTS to predict good outcome in patients with anterior circulation stroke after endovascular therapy.

Second, the DWI-ASPECTS cannot substitute for DWI lesion volume in patients with anterior circulation stroke and an intermediate ASPECTS of 4-6 because an intermediate DWIASPECTS corresponds to a wide range of lesion volumes. ${ }^{28}$ It has been reported that DWI lesion volume is a strong predictor of clinical outcome after endovascular treatment. ${ }^{16,29}$ Recently, Ribo et $\mathrm{al}^{29}$ suggested the concept of the maximal admission lesion volume compatible with favorable outcome, which was defined as the admission core volume above which the possibility of favorable outcome ( $\mathrm{mRS} 0-2$ ) was $<10 \%$ in patients with acute anterior circulation stroke. In their study, maximal admission lesion volume compatible with favorable outcome was found to

Table 3: Logistic regression analysis of predictors of good outcome

\begin{tabular}{|c|c|c|c|c|c|c|}
\hline & Unadjusted OR & $95 \% \mathrm{Cl}$ & $P$ Value & Adjusted OR & $95 \% \mathrm{Cl}$ & $P$ Value \\
\hline Age per 1-yr increase & 0.947 & $0.918-0.976$ & $<.001$ & 0.941 & $0.909-0.974$ & .001 \\
\hline Baseline NIHSS, per 1-point increase & 0.900 & $0.834-0.971$ & .006 & - & - & - \\
\hline Time to treatment & 1 & $0.996-1.004$ & .999 & - & - & - \\
\hline Modified $\mathrm{TICl} 2 \mathrm{~b}$ or 3 & 9.455 & $2.725-32.808$ & $<.001$ & 8.511 & $2.298-31.525$ & .001 \\
\hline Symptomatic hemorrhage & 0.213 & $0.240-1.859$ & .125 & - & - & - \\
\hline DWI-ASPECTS, per 1-point increase & 1.150 & $0.930-1.421$ & .196 & - & - & - \\
\hline DWI-ASPECTS $\geq 7$ vs $<7$ & 1.603 & $0.823-3.120$ & .165 & - & - & - \\
\hline
\end{tabular}




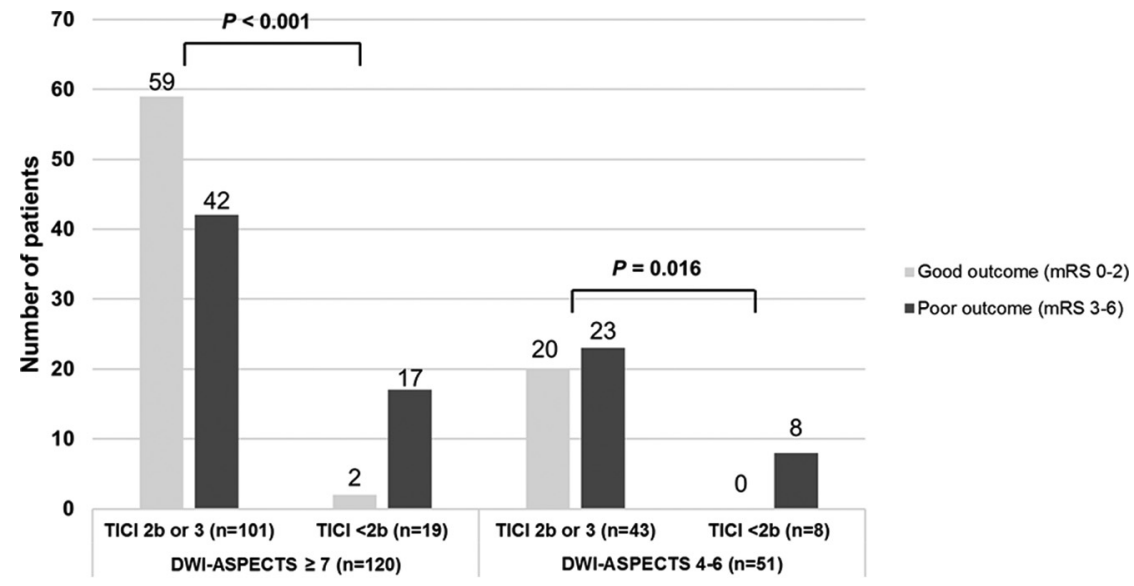

FIG 3. Impact of successful revascularization on functional outcome according to DWI-ASPECTS.
DWI-ASPECTS on outcome may be partly because patients with a low DWI-ASPECTS of $\leq 3$ were not included. Previous studies showing a positive correlation between DWI-ASPECTS and outcome after endovascular therapy mostly included patients with an ASPECTS of $0-3$, and most of these patients had an mRS of 5-6, which might explain any statistically significant relationship between DWI-ASPECTS and outcome in their analyses. , $^{9,14}$

Although the DWI-ASPECTS may not be suitable for prediction of infarction volume and outcome in patients with intermediate-to-high ASPECTS, it can still be used to predict a lesion volume cutbe $39 \mathrm{~mL}$ and was shown to be a potent predictor of favorable outcome (OR, 9.3; $P=.01$ ), independent of recanalization and age. $^{29}$

DWI-ASPECTS is commonly used as surrogate for lesion volume to save time in an acute setting. However, a previous study showed that DWI lesion volume in patients with a DWIASPECTS 4-6 ranged from 10 to $197 \mathrm{~mL}$ (median, $66 \mathrm{~mL}$; IQR, 41-97 mL). ${ }^{28}$ An explanation for this variability is that ASPECTS regions are weighed unequally and in favor of the striatocapsular region. ${ }^{30}$ Another recent study showed that there is a striking disparity of DWI ASPECTS-DWI lesion volume correlations between the superficial (cortical) and the deep (striatocapsular) MCA regions. ${ }^{31}$ DWI-ASPECTS showed only a poor correlation to DWI lesion volume for stroke lesions in the striatocapsular region in that study. In this regard, patients with a DWIASPECTS of 4-6 but small ischemic lesion volume are likely to have a chance of a good outcome after stent-retriever embolectomy, especially when successful revascularization occurs.

Third, patients with a high DWI-ASPECTS were significantly older than those with an intermediate ASPECTS, and age was one of the independent predictors of good outcome in the present study. This might attenuate the positive effect of DWI-ASPECTS on outcome in the high DWI-ASPECTS group and thus contribute to the statistical insignificance of the DWI-ASPECTS.

Our study result has an important clinical implication, in that patients with an intermediate DWI-ASPECTS otherwise eligible for endovascular therapy, especially with scores of 4 and 5, may not be excluded from stent-retriever embolectomy or stroke trials on the basis of the DWI-ASPECTS alone. Our study suggested that the DWI-ASPECTS may not be a relevant imaging predictor of outcome in patients with anterior circulation stroke presenting within 6 hours. The DWI-ASPECTS was not significantly associated with outcomes in univariate and multivariate analysis in the present study. The results of our study are consistent with a recent study by Danière et al. ${ }^{18}$ Among 26 patients with a DWIASPECTS of $<5$ in their study, $60 \%$ of patients younger than 70 years of age had a good outcome, whereas $10 \%$ of those 70 years of age and older had a good outcome after stent-retriever embolectomy. The authors suggested that younger patients may still benefit from recanalization despite a DWI-ASPECTS of $<5$. In the present study, the absence of statistical significance of point of $>100 \mathrm{~mL}$, which corresponds to a traditional concept of greater than one-third of the middle cerebral artery territory and serves as an exclusion criterion for endovascular therapy in ongoing trials. In a study by de Margerie-Mellon et al, ${ }^{28} 94 \%$ of patients $(32 / 34)$ with a DWI-ASPECTS of $\leq 3$ had a lesion volume of $>100$ $\mathrm{mL}$ and the lowest lesion volume in those patients was $93 \mathrm{~mL}$. While DWI-ASPECTS may not predict outcome in patients with acute anterior circulation stroke, it may be useful for defining the presence of a benign imaging pattern to establish candidacy in the new embolectomy era.

Our study has several limitations, including a retrospective and monocentric study design. We did not measure DWI lesion volume and thus did not examine the relationship between lesion volume and ASPECTS. However, that relationship has been well documented in previous studies, ${ }^{28,31}$ and the aim of our study was to investigate whether the DWI-ASPECTS can be used as an imaging predictor of clinical outcome after stent-retriever embolectomy in anterior circulation stroke. The patients were selected for endovascular therapy by using perfusion imaging and a target mismatch profile. The results of the study might be different if patients with a nontarget mismatch profile were included. Finally, the patient number in the high DWI-ASPECTS group was larger than that of the intermediate group.

\section{CONCLUSIONS}

Our study suggested that treatment outcomes were not different between patients with a high DWI-ASPECTS of 7-10 and those with an intermediate DWI-ASPECTS of 4-6 who underwent stent-retriever embolectomy for acute anterior circulation stroke. Thus, patients with intermediate DWI-ASPECTS otherwise eligible for endovascular therapy may not be excluded from stentretriever embolectomy or stroke trials.

\section{REFERENCES}

1. Berkhemer OA, Fransen PS, Beumer D, et al. A randomized trial of intraarterial treatment for acute ischemic stroke. N EnglJMed 2015; 372:11-20 CrossRef Medline

2. Campbell BC, Mitchell PJ, Kleinig TJ, et al; EXTEND-IA Investigators. Endovascular therapy for ischemic stroke with perfusion-imaging selection. N Engl J Med 2015;372:1009-18 CrossRef Medline

3. Goyal M, Demchuk AM, Menon BK, et al; ESCAPE Trial Investiga- 
tors. Randomized assessment of rapid endovascular treatment of ischemic stroke. $N$ Engl J Med 2015;372:1019-30 CrossRef Medline

4. Saver JL, Goyal M, Bonafe A, et al; SWIFT PRIME Investigators. Stent-retriever thrombectomy after intravenous t-PA vs. t-PA alone in stroke. $N$ Engl J Med 2015;372:2285-95 CrossRef Medline

5. Jovin TG, Chamorro A, Cobo E, et al; REVASCAT Trial Investigators. Thrombectomy within $\mathbf{8}$ hours after symptom onset in ischemic stroke. N Engl J Med 2015;372:2296-306 CrossRef Medline

6. Yoo AJ, Chaudhry ZA, Nogueira RG, et al. Infarct volume is a pivotal biomarker after intra-arterial stroke therapy. Stroke 2012;43: 1323-30 CrossRef Medline

7. Shi ZS, Liebeskind DS, Xiang B, et al; Multi MERCI, TREVO, and TREVO 2 Investigators. Predictors of functional dependence despite successful revascularization in large-vessel occlusion strokes. Stroke 2014;45:1977-84 CrossRef Medline

8. Linfante I, Starosciak AK, Walker GR, et al. Predictors of poor outcome despite recanalization: a multiple regression analysis of the NASA registry. J Neurointerv Surg 2015 Jan 6. [Epub ahead of print] CrossRef Medline

9. McTaggart RA, Jovin TG, Lansberg MG, et al; DEFUSE 2 Investigators. Alberta stroke program early computed tomographic scoring performance in a series of patients undergoing computed tomography and MRI: reader agreement, modality agreement, and outcome prediction. Stroke 2015;46:407-12 CrossRef Medline

10. Barber PA, Demchuk AM, Zhang J, et al. Validity and reliability of a quantitative computed tomography score in predicting outcome of hyperacute stroke before thrombolytic therapy: ASPECTS Study Group-Alberta Stroke Programme Early CT Score. Lancet 2000; 355:1670-74 CrossRef Medline

11. Barber PA, Hill MD, Eliasziw M, et al; ASPECTS Study Group. Imaging of the brain in acute ischaemic stroke: comparison of computed tomography and magnetic resonance diffusion-weighted imaging. J Neurol Neurosurg Psychiatry 2005;76:1528 -33 CrossRef Medline

12. Butcher K, Parsons M, Allport L, et al; EPITHET Investigators. Rapid assessment of perfusion-diffusion mismatch. Stroke 2008;39:75-81 CrossRef Medline

13. Kimura K, Iguchi Y, Shibazaki K, et al. Large ischemic lesions on diffusion-weighted imaging done before intravenous tissue plasminogen activator thrombolysis predicts a poor outcome in patients with acute stroke. Stroke 2008;39:2388-91 CrossRef Medline

14. Inoue M, Olivot JM, Labreuche J, et al. Impact of diffusion-weighted imaging Alberta stroke program early computed tomography score on the success of endovascular reperfusion therapy. Stroke 2014;45: 1992-98 CrossRef Medline

15. Vogt G, Laage R, Shuaib A, et al; VISTA Collaboration. Initial lesion volume is an independent predictor of clinical stroke outcome at day 90: an analysis of the Virtual International Stroke Trials Archive (VISTA) database. Stroke 2012;43:1266-72 CrossRef Medline

16. Olivot JM, Mosimann PJ, Labreuche J, et al. Impact of diffusionweighted imaging lesion volume on the success of endovascular reperfusion therapy. Stroke 2013;44:2205-11 CrossRef Medline

17. Lin K, Lee SA, Zink WE. What ASPECTS value best predicts the $100-\mathrm{mL}$ threshold on diffusion weighted imaging? Study of $150 \mathrm{pa}-$ tients with middle cerebral artery stroke. J Neuroimaging 2011;21: 229-31 CrossRef Medline
18. Danière F, Lobotesis K, Machi P, et al. Patient selection for stroke endovascular therapy-DWI-ASPECTS thresholds should vary among age groups: insights from the RECOST study. AJNR Am J Neuroradiol 2015;36:32-39 CrossRef Medline

19. Singer OC, Kurre W, Humpich MC, et al; MR Stroke Study Group Investigators. Risk assessment of symptomatic intracerebral hemorrhage after thrombolysis using DWI-ASPECTS. Stroke 2009;40: 2743-48 CrossRef Medline

20. Nezu T, Koga M, Kimura K, et al. Pretreatment ASPECTS on DWI predicts 3-month outcome following rt-PA: SAMURAI rt-PA Registry. Neurology 2010;75:555-61 CrossRef Medline

21. Aoki J, Kimura K, Shibazaki K, et al. DWI-ASPECTS as a predictor of dramatic recovery after intravenous recombinant tissue plasminogen activator administration in patients with middle cerebral artery occlusion. Stroke 2013;44:534-37 CrossRef Medline

22. Yoon W, Jung MY, Jung SH, et al. Subarachnoid hemorrhage in a multimodal approach heavily weighted toward mechanical embolectomy with Solitaire stent in acute stroke. Stroke 2013;44:414-19 CrossRef Medline

23. Kim SK, Yoon W, Moon SM, et al. Outcomes of manual aspiration thrombectomy for acute ischemic stroke refractory to stent-based embolectomy. J Neurointerv Surg 2015;7:473-77 CrossRef Medline

24. Zaidat OO, Yoo AJ, Khatri P, et al; STIR Revascularization working group, STIR Thrombolysis in Cerebral Infarction (TICI) Task Force. Recommendations on angiographic revascularization grading standards for acute ischemic stroke: a consensus statement. Stroke 2013;44:2650-63 CrossRef Medline

25. Rha JH, Saver JL. The impact of recanalization on ischemic stroke outcome: a meta-analysis. Stroke 2007;38:967-73 CrossRef Medline

26. Abilleira S, Cardona P, Ribó M, et al; Catalan Stroke Code and Reperfusion Consortium. Outcomes of a contemporary cohort of 536 consecutive patients with acute ischemic stroke treated with endovascular therapy. Stroke 2014;45:1046-52 CrossRef Medline

27. Yoon W, Kim SK, Park MS, et al. Endovascular treatment and the outcomes of atherosclerotic intracranial stenosis in patients with hyperacute stroke. Neurosurgery 2015;76:680-86; discussion 686 CrossRef Medline

28. de Margerie-Mellon C, Turc G, Tisserand M, et al. Can DWIASPECTS substitute for lesion volume in acute stroke? Stroke 2013; 44:3565-67 CrossRef Medline

29. Ribo M, Tomasello A, Lemus M, et al. Maximal admission core lesion compatible with favorable outcome in acute stroke patients undergoing endovascular procedures. Stroke 2015;46:2849-52 CrossRef Medline

30. Phan TG, Donnan GA, Koga M, et al. The ASPECTS template is weighted in favor of the striatocapsular region. Neuroimage 2006; 31:477-81 CrossRef Medline

31. Schröder J, Cheng B, Ebinger M, et al; STIR and VISTA Imaging Investigators. Validity of acute stroke lesion volume estimation by diffusion-weighted imaging-Alberta Stroke Program Early Computed Tomographic Score depends on lesion location in 496 patients with middle cerebral artery stroke. Stroke 2014;45:3583-88 CrossRef Medline 